\title{
Research in Health Services
}

\section{MARCUS ROSENBLUM}

Excerpts included in this report are from papers and critiques prepared for the Health Services Research Prepublication Conference, held October 15-16, 1965, at the University of Chicago Center for Continuing Education. Coordinator and chairman of the conference was Dr. Donald Mainland of New York University. The conference was sponsored by the Health Services Research Study Section with PHS grant No. CH-00108 from the Division of Community Health Services. Dr. Kerr L. White, division of medical care and hospitals, Johns Hopkins University School of Hygiene and Public Health, acted as chairman of the study section. Dr. Thomas McCarthy, Division of Research Grants, National Institutes of Health, Public Health Service, is executive secretary of the study section.

$\mathrm{I}^{\mathrm{N}}$ THE 12 months ending June 30, 1964, funds totaling $\$ 35.4$ billion were used for health and medical care in the United States. This sum was 5.9 percent of the gross national product. And yet relatively little investment is made in research in the organization of health services, their goals and policies, methods of evaluating the effectiveness and efficiency of health services, facilities and equipment, the economics or the market for health services, their administration, or the basic processes of health communications.

This is not to say that the subjects have been completely ignored. Systematic study of health services, especially of clinical practices, has an ancient history. At the same time, research in these identified categories of health service has yet to be established as a formal discipline. Except for a few conferences on studies in health economics or the health conditions of large populations, the conference in Chicago might be regarded as an initial event in the conscious evaluation of methods of research in health services.

Few persons attending the meeting were identifiable as specialists of research in health services. Rather, they were specialists of another kind: economists, clinical physicians, psychologists, behavioral scientists, hospital administrators, sociologists, biometricians, architects, health officers, engineers, information analysts, and at least one mathematical physicist engaged in industrial operations research. With such diversity of background and interest, it might have been expected that the conference would underline areas of difference more than areas of agreement, but in fact there was a consensus undiminished by the variety of strategies and tactics argued.

As one speaker put it toward the close of the second session, research has three aspects: the collection of data; the formulation of models, hypotheses, or theories; and experimental applications. These do not follow in orderly sequence, chronologically or intellectually. They mingle. There is no question of one being more important than another. For example, while it was granted that a general theory for research in health services could be as fruitful as a general theory in physics, it was held that

Mr. Rosenblum is deputy special assistant to the Surgeon General (science information), Public Health Service. 
search for a general theory must not abandon the other aspects of research. The interest in general theories as models for research was matched by interest in the acquisition of information and in pragmatic experiments that respond to acute social needs. If the meeting reached a consensus on theories of research, this acceptance of interdependence appears to have been it.

The primary object of the conference was to review the eight papers and the critiques prepared in advance. They were the bases for the discussions and the exchange of views and comments. The papers are to be published in modified form in the Milbank Memorial Fund Quarterly. A brief summary report of the conference has been distributed in a limited edition.

Instead of reading their papers or comments, the participants had their texts distributed in advance so that all who attended the meeting might be free to exchange views freely and extemporaneously. In addition to the analytical criticism, the program was rich in reviews of pertinent literature and evaluation of the outstanding contributions. Regrettably, little of that information or of the logical processes of evaluation can be conveyed in this report. What follows consists of a few selected but not necessarily representative quotations from the papers and critiques presented.

Odin W. Anderson, Center for Administrative Studies, University of Chicago: Social research and public policy: An examination of its role in the health field.

It seems that systematic data gathering and research do not appear until a public policy consensus has emerged that provides the framework in which social and economic research bearing on policy takes place, and such a framework quite unconsciously establishes the guidelines for the selection of data.

In the annual report of the Brookings Institution in 1961, its President, Robert D. Calkins, wrote:

In both foreign and domestic matters, policy issues have become so complex and so far-reaching in their consequences that they cannot be dealt with effectively on the basis of prevailing opinion, intuition, and off-hand judgment. Research, special knowledge, and expert advice are necessary.
In many areas, policy and action continue to be improvised on the basis of prevailing beliefs more than on an informed appraisal of issues and alternatives.

If this is true for public policy in general, as Calkins implies, it is certainly true for health services in particular. The health field has such an aura of lifesaving, altruism, and alleviation of pain and suffering that realistic thinking about money, resources, and implementation is inhibited. Somehow, the health services establishment is expected to transcend such mundane realities.

It is self-evident that our health system-and the systems in Europe, too, for that matterwas not the result of a grand design, but rather the result of more or less spontaneous absorption of new medical developments in the health services and social structures existing during the latter part of the 19th century. .. . Fundamental values in society are evolved from the life experiences of people and not from scientific research by dispassionate scholars. . . A fundamental value subscribed to by all groups within the liberal-conservative spectrum is that all people should have relatively equal access to health services regardless of financial status.

If personal health services had been regarded as simply another commodity which could be sold in the open market as any other commodity, there would still have been research, but mainly of a market and price-trend nature. ... Research that has been conducted was motivated in the spirit of promoting relatively equal accessibility by some means or other, and from one source of funds or other. ... Research so far has been pervaded with a certain naivete that we can have an optimum health service if doctors become more altruistic, patients wise, health insurance agencies would reduce cost of administration, and so on. I can sense no sophistication in the assessment of possibilities, of the tolerances of providers of services, the recipients of services, and the health insurance agencies as to what is a workable equilibrium between them.

How we select problems for research, how we develop adequate methodology, and how we interpret and translate findings to application should assist us in assessing the net results of 
possible alternatives, assuming this degree of rationality is possible. Short of this, however, we can measure the relative effects of countervailing powers applied by the providers of service, the recipients of service, and the sources and control of funds on the dynamics of the health services system, on the assumption that a resolution acceptable to all parties simultaneously is unattainable, only resolutions acceptable to one at a time and then relatively temporarily.

James P. Dixon, Antioch College, Yellow Springs, Ohio: Reviewing paper by Anderson.

It may be that for research to be more effective in the field of social policy for health services, the role of the researcher may need to change. Anderson touches upon this point when he mentions the roles played by Trussell [Columbia University, N.Y.C.] and McNerney [Blue Cross Association]. One sees in their roles less the traditional role of the pure researcher than a mixture of elements of research and politicsan acceptance perhaps of the principle that information is power and that data gathered in a pragmatic fashion and used with political astuteness can influence the course of public policy.

There is a kind of research into continuing programs that needs to be built into every operational agency. . . . This kind of evaluation has the effect of requiring the operating agency to consider its goals and procedures in the light of current knowledge. . . A A a matter of public policy ... research and development should be included as a normal function of every operational agency.

Selma Mushkin, Council of State Governments, Washington, D.C.: Reviewing paper by Anderson.

An increasing number of research studies are directed to $(a)$ defining the nature of investment in people, $(b)$ measuring the size of this investment, and $(c)$ showing the rate of return on this human capital. Such concepts of human capital formation have been largely the work of Professor Theodore W. Schultz [University of Chicago] and of those that he has encouraged.
Though the research that has been done describes primarily education as an investment in people, the conceptual framework of these studies applies as well to the case of health.

The human capital formation by health care for a population may be counted, for example, at cost - the cost of environmental and curative health services embodied over their lifespans in each of the age cohorts in the present labor force. Costs for this purpose may be set at the cost of acquisition of the health services in the years they were acquired, at either a replacement cost basis or at constant prices (prices prevailing in a base year) . . . . The health program stock of the 1960 work force was estimated to have been in excess of $\$ 200$ billion in 1960 dollars and over $\$ 130$ billion in terms of prices at time of acquisition.

As the value of conventional property is determined by its earning power, so the value of investment in human capital may be measured by the increased earning power of individuals. ... What is the value of the work force added and of the capital in future earnings added by the reduction in deaths that occurred between 1900 and 1960? The labor force in the United States was found to be 25 percent higher than it would have been if 1900 mortality rates had continued unchanged through the 60 -year period $1900-60$, and the capital value in $1960 \mathrm{ac}-$ crued due to the change in mortality experience had exceeded $\$ 800$ billion.

The underlying problem thus addressed is: What is contributed by changes in the quality of people to economic growth? Is the return on improving the quality of people more or less than the return on alternative uses of the resources?

Denison [Committee for Economic Development, N.Y.] . . sought to quantify the effect on historical growth rates of the U.S. economy of a series of "social" policies such as the shorter work week, increased educational opportunities-factors previously neglected in studies of economic growth. Denison's work indicates that various policies can raise the growth rate but that a rise of 0.1 percentage points per year would require such steps as: prevention of half 


\section{Conference Participants}

Dr. Odin W. Anderson

Dr. Robin F. Badgley

Dr. Gilbert Barnhart

Dr. Henrik Blum

Joseph Blumenkranz

Dr. Philip D. Bonnet

Ray E. Brown

Dr. Carol W. Buck

Dr. Eveline M. Burns

Franklin B. Caffee

Dr. Duncan W. Clark

Dr. Eugene A. Confrey

J. B. Cornish

Lord Llewelyn-Davies

Dr. James P. Dixon
Dr. Avedis Donabedian

Dr. Edward Dunner

Dolly W. Estel

Dr. Jacob J. Feldman

Dr. Paul J. Feldstein

G. O. Fiedler

Dr. Charles D. Flagle

Evelyn Flook

Dr. Howard E. Freeman

Dr. Eliot Freidson

Dr. Robert J. Haggerty

Dr. Gerhard Hartman

Dr. William J. Horvath

Dr. Herbert E. Klarman

Dr. Sol Levine
Dr. Donald Mainland

Dr. W. Fred Mayes

Dr. Thomas McCarthy

Gordon McLachlan

Matthew F. McNulty, Jr.

Ilona Malstrads

Dr. Jonas N. Muller

Dr. Selma Mushkin

Quigg Newton

Andrew Pattullo

Dr. L. B. Pett.

Prof. R. W. Revans

Dr. Donald C. Riedel

Dr. Alexander Robertson

Marcus Rosenblum
Dr. Leonard S. Rosenfeld

Dr. Irwin M. Rosenstock

Dr. Gerald Rosenthal

Dr. Paul J. Sanazaro

Dr. W. Richard Scott

Sam Shapiro

Dr. Frederick D. Sheffield

Dr. Cecil G. Sheps

Dr. James D. Thompson

Dr. James D. Wharton

Dr. Kerr L. White

Dr. Charles R. Wright

Dr. Wesley O. Young

Dr. Irving K. Zola the deaths that would otherwise occur up to 1980 among individuals under 65 years of age; reduction of half the time lost from work owing to sickness and accidents. While Denison did not undertake as part of his study to quantify the share of the historic growth in the United States attributable to health care, in a later study Denison's technique of analysis was applied to the reduction in death rates with the finding that the national income in 1960 was 18 percent higher than it would have been had death rates of 1900 continued unchanged throughout the period and that the growth rate per annum over the period was raised 0.27 percentage points above what it otherwise would have been.

To apply the cost-benefit tool generally in budget decisions, both costs and benefits must be measurable. Improved measurement requires fuller identification of costs, including positive or negative costs incurred in related programs; for example, as a consequence of increased outlays for education, reduction in venereal disease costs may result.

The time may now be ripe for a reexamina. tion of measurement concepts and techniques.

We also face the research task of identifying costs and benefits to evaluate in the relation of specific health measures to a general "bundle of investments in people." As a foundation for cost-benefit analysis, research is needed on combinations of education, health, and welfare services that will most effectively and efficiently enlarge the productive capacity of people, and the effectiveness of their consumption outlays.

Moreover, research is urgently needed to permit some evaluation of the time-cost tradeoff in spending for health. For example, by spending far more now on cancer research, the time elapsing before some curative or preventive health care becomes available may be shortened. Is it possible to assess the reduction in time per additional $\$ 1$ million spent? Or over what period of time can we deal with children's dental problems without incurring additional costs of $\$ 1$ billion, $\$ 2$ billion, and so on, in additional worktime lost in the adult population?

Studies related to the organization of the "market" for health services... (a) apply new research tools to analysis of familiar problems such as the "region" for the provision of hospital care, (b) examine problems such as hospital costing or returns on the education of physicians, or $(c)$ ask new questions and in a different way.

Medical care is neither provided by health practitioners nor acquired by the consumers, under the "rules of the game" that govern a market system. Without elaborating here the forces that make for special characteristics of 
the medical care market and distinguish it from the basic design of our economy generally, let me quickly note: $(a)$ the consumer's preference is to avoid the necessity for medical care, $(b)$ that his spending decisions about medical care when he is well differ considerably from his decisions on this care when illness strikes, $(c)$ that he tends to discount his medical care needs in the future, and $(d)$ that there are large external benefits received in the community from health care outlays made by others and, accordingly, that medical services would be undervalued, and insufficient resources allocated to providing these services, if market forces alone prevailed. What I wish to emphasize here, however, is that an understanding of the processes of innovation within our existing medical care organization is essential.

The absence of functioning competition under a price-profit market retards such innovation. Instruments have to be established for planning for the "economy of medicine" in the absence of an appropriate market system. Institutional arrangements have to be created for new social inventions that give flexibility and vitality to this planning in a mixed economy that has a much higher component of price-profit guidelines than does the health industry.

What are the conditions required for adoption of new organizational arrangements? We need to know considerably more than we do about decision-making processes for the nonprofit organizations that predominate in the health field. What has retarded the development of arrangements for bringing the complex medical team to patients outside of hospitals? When decisions are constrained by voluntary giving, the volume of services may be unduly restricted. Perhaps more reliance on the pricing of services and fees would facilitate a larger volume of services.

Henrik Blum, Contra Costa County Health Officer, Oakland, Calif.: Research in organization of agencies providing community health services.

Those engaged in providing community health services will be forced to concern themselves with the social reasons that are operating to make people too preoccupied, unoccupied, or uneducated to hear or understand health messages.

Failure or unwillingness to look at and act upon how basic social needs affect ability to deliver services or utilities is a major reason that health departments and medicine in general have achieved such an impressive lack of improvement in health status for large segments of our population.

The current pressures for new programs and expansions of old ones are based on changing national values, not on research-produced information. Their demands exceed most agencies' capabilities, and their value burden and political origin tend to further dampen the research outlook of more traditional, nonacademic service agency administrators.

The pressures for change in agency services that apply so broadly across the nation are identifiable in great part. Although they discourage local research by their weight and frequency, they do allow a chance to measure simultaneously in many quite different environments and structures the impact of the same phenomena.

Howard E. Freeman, Brandeis University, Waltham, Mass.: Reviewing paper by Blum.

It is necessary to lay out some priorities for research on the organization of community health services. .. . The major emphasis should be on studies that lead to either socialpolicy changes or technological changes in the field.

Virtually all innovations or modifications in programs require the support and approval of public officials not identified with the health field and of various power groups in the community.

Technological research is of minimal importance in comparison with social-policy studies.

Ideally, we need a cadre of persons who are both program and research sophisticated. . . . One of the reasons for so little evaluative activ- 
ity and opposition to it . . . is the failure of social researchers to take a proper role in terms of the development of evaluative studies. . . . It is not possible for the researcher to assert that he is a scientist who stays out of the organization and yet can provide sharp findings on practitioners' work or efficiency.

As one moves to new forms of medical practice to meet the needs of specific groups or to most efficiently allocate resources, the utility of various channels of interpretation and communication need to be examined. Not only is the issue of communication within the client network an important one, but attention must be paid to problems of interpersonal arrangements among professionals.

A whole series of experiments would be most desirable and useful regarding alternative means for setting personnel requirements and outlining organizational structures in order to avoid the rigidities of current employment and personnel policies.

Cecil G. Sheps, Beth Israel Medical Center, New York, N.Y.: Reviewing paper by Blum.

In view of the great need for improving the efficiency and effectiveness of the functions of most, if not all, health agencies, all types of research should be welcomed, as long as the purpose, potentiality, and limitations of each are clearly understood.

Research opportunities include studies of the methods of delineating the objectives of health service organizations and the methods of organization and administration of facilities, personnel, and services conducive to the achievement of specific objectives with maximum efficiency and effectiveness.

Avedis Donabedian, University of Michigan, Ann Arbor: Evaluating the quality of medical care.

The search for easy ways to measure a highly complex phenomenon such as medical care may be pursuing a will-o'-the-wisp. The use of simple indexes in lieu of more complex measures may be justified, as M. Sheps has suggested, by demonstrating high correlations between them. But in the absence of demonstrated causal links, this may be an unsure foundation upon which to build. On the other hand, each index is a measure of a dimension or ingredient of care. Judiciously selected multiple indexes may, therefore, constitute the equivalent of borings in a geological survey which yield sufficient information about the parts to permit reconstruction of the whole. The validity of inferences about the whole will depend, of course, on the extent to which there are internal continuities in the individual or institutional practice of medicine.

A great deal of effort goes into the development of criteria and standards which are presumed to lend stability and uniformity to judgments of quality, and yet this presumed effect has not been empirically demonstrated. Nor do we know how far explicit standardization must go before there are appreciable gains in reliability. One must also consider whether with increasing standardization there is so much loss of the ability to account for unforeseen elements in the clinical situation that one obtains reliability at the cost of validity.

A review of the studies of quality shows a certain discouraging repetitiousness in basic concepts, approaches, and methods. . . . Further substantive progress . . . is likely to come from a program of research in the medical care process itself rather than from frontal attacks on the problem of quality.

There is need for greater neutrality and detachment in studies of quality. More often one needs to ask, "What goes on here?" rather than, "What is wrong, and how can it be made better?" This does not mean that the researcher disowns his own values or social objectives. It does mean, however, that the distinction between values, and elements of structure, process or outcome, is recognized and maintained and that both are subjected to equally critical study. It is partly to achieve this kind of orientation that the author has advocated a shift in emphasis from preoccupation with evaluating quality to concentration on understanding the medical care process itself. 
Sam Shapiro, Health Insurance Plan of Greater New York: Reviewing paper by Donabedian.

The subject of quality of care cannot be pursued far without becoming directly concerned with the specific forces that generate an interest in it. These forces are by and large actionmotivated whether they originate in issues that have an administrative or legislative end point in mind or in questions related to slowly evolving conditions. Few if any of the studies are conducted to measure quality of care in the abstract, and all are subject to compromises in methodology.

Attention is focused on the individual practitioner-his diagnostic ability, his use of medical resources, his management of specific diseases, and so forth. In view of the orientation of past investigations and the direction many studies will undoubtedly take in the future, this emphasis is understandable. But it detracts from the importance of viewing quality of medical care in a broad framework-one in which the unit of observation is the population "at risk" rather than the individual practitioner or patient. With this perspective, assessment of medical care becomes heavily concerned with questions related to distribution, accessibility, and use of medical services, and outcome or effect of medical care on health status.

Paul J. Feldstein, University of Michigan, Ann Arbor: Research on the demand for health services.

Different forms of organizing medical care have their effect in the manner in which the components of care are used by the physician. To be effective (that is, to result in a lower total cost of care to the community), new forms of organization must first enable the physician to produce care of given quality with lower cost components; for example, to substitute outpatient care for hospitalization when medically possible. At the same time, they must allow the physician to act in the patient's interest; for example, to substitute insured for uninsured services. Second, they must not change the relative cost to the physician for using a new set of components of care, or they may lower his costs; for example, by requiring less of his time, increasing his convenience of performing his tasks, increasing his productivity, resulting in economies of scale, and so on. The important point is that if a change in organization is to be accepted, it must result in a lower cost to the patient, the physician, or both.

Unless we know the illness pattern and how it may shift with changes in, for example, income levels, we cannot determine whether future differences in expenditures between highand low-income persons represent unfilled medical needs.

Results derived by statistical techniques, no matter how highly sophisticated, cannot give substance to poorly formulated hypotheses or be any more reliable than the raw data.

Regarding the role of information and knowledge ... . it would be important to determine whether this information is transmitted so that those making decisions on health care may base them upon the most complete knowledge possible. How knowledgeable is the practitioner of health care regarding the changes in medical practice and in the use of alternative forms of care in treatment? Rapid dissemination of information to the physician will enable him to produce better medical care at lowest cost to his patient and, one hopes, to the community. To the extent that variations in use are a result of differences in information, increased information will decrease these variations. What is the discrepancy between medical need and demand for care? To the extent that financial resources are not a constraint, an increase in information about the benefits of care would help to reduce the difference between need and demand for medical treatment in circumstances where the apparent benefits to the individual from undertaking such treatment greatly exceed the expected cost.

Donald C. Riedel, Blue Cross Association, Chicago, Ill.: Reviewing paper by Feldstein.

Our best data on the demand for personal health services come principally from two sources : household interviews and hospital med- 
ical records. We have no data on physicians' practices crucial to a real understanding of the medical care process. For example, we have no national data on the volume or nature of the patient load, the treatment rendered in the office, the referral patterns practiced, the types or costs of equipment in physicians' offices, the qualifications of assisting personnel, the methods of fee-setting employed, and so on. In terms of needed research, we are probably in most need of some national benchmarks on physicians' office practices, supplemented by more detailed analyses of "patient flow" in a smaller geographic area. Until we can get more specific about the "office visit," we will never get past the "paper model" demand for medical care.

Lord Llewelyn-Davies, University College, London: Facilities and equipment for health services: Needed research.

It is not easy to evaluate the extent to which available research data have been used in practice, but its impact appears to have been considerable. Few major hospital authorities and few specialist architects and engineers today work in ignorance of the research material available. Nevertheless, it is probably true that available knowledge is not always completely understood or wisely applied. Plans for new hospitals in most countries show the influence of research into function, but sometimes a particular research finding is seized on and given a priority out of all proportion to its real worth. For example, certain studies of limited aspects of function in nursing units have been held to justify circular and star shaped buildings. Elsewhere national or local hospital authorities have sometimes used the umbrella of research to justify rather rigid standards. But it may be said that, on the whole, failures in practice come from lack of wisdom and breadth of vision in those applying research results, rather than any intrinsic weakness in research material itself.

Health care often requires the systematic monitoring of human reactions, both physiological and psychological. Therefore, a health building is a convenient place in which to study the impact of architecture on people.
Owing to the fact that buildings are relatively longlasting, many social functions have to be performed in buildings designed for another purpose. Thus buildings influence group behavior in an accidental and often undesirable way.

It will only be meaningful to consider the relation of building design to human behavior if we already have a clear view of what the aims of the health service really are.

From the point of view of the patient, the doctor with whom he has his first consultation, the diagnostic service to which he is referred, the hospital or other institution where he may go for treatment, and the rehabilitation center which takes care of the adjustment between a spell in the hospital and a patient's return to normal living are all part of a continuous system.

In a general systems analysis of the health services for a region it is necessary to take into account not merely social and medical parameters but also the cost and distribution of the health plant.

The first necessity for any study of plant stock must obviously be some system of inventory. Surprising as it may seem, even in countries where substantial parts of the health service are under integrated national or regional control, no complete inventory of buildings or equipment usually exists. ... The information exists, but it is buried in the records and files of a number of different organizations within the area.

It is argued that the concentration of psychiatric patients in large centralized institutions is undesirable on medico-social grounds. Against this, the main argument generally adduced is the greater economy of the provision of care in massive centralized institutions. The validity of this argument and the weight it should be given are open to question, but the matter cannot really be debated unless there is some effective description of the health plant involved in centralized or decentralized situations. 
Town planning literature discusses in depth how the design of towns should attempt to cater to the needs of many types of buildings, but health buildings are rarely mentioned. . . . It is at least arguable that the structure of the health service from the doctor up to the regional medical center is a major element in the arrangements of cities.

In any case it would seem wrong that the location of health buildings should be wholly determined by pressure of local land values.

Joseph Blumenkranz, Joseph Blumenkranz \& Associates, New York City: Reviewing paper by Llewelyn-Davies.

Unless we assume new attitudes in matters of health, we will bog down in a morass of meaningless figures. We must raise our sights to the potential of the scientific revolution and not cringe at the level of current health care which represents niggardly crumbs of our productive capacity. One statistic, however, might prove helpful in this educational process: it is the percentage of the gross national product of the countries of the world spent on health, in comparison with other major expenditures. Such comparisons might serve as an awakening to the low esteem in which the national health picture is presently regarded.

Research should look forward to the establishment on national as well as international scope of electronic data storage and retrieval networks in health care. With the aid of such networks of computerized data, the doctor as well as other members of a health-care team will be able to obtain rapidly information desired for diagnosis and therapy, and even obtain verification of diagnosis. With the wealth of statistics thus almost instantaneously available, diagnosis and treatment can become less and less intuitive and more and more objective.

Another major benefit to be derived by health care from computers is in their ability to classify, store, and retrieve valuable data with unmatched scope and incomparable speeds. Currently, there are about 2,000 scientific papers published every week throughout the world. It goes without saying that the conventional means of translation, cataloging, and referral to this flood of research sources cannot cope with the information explosion; consequently, a great deal of this valuable and usable material lies fallow or buried. However, with the aid of computers, this resource can be classified, cataloged, stored, and retrieved almost instantaneously.

Gerhard Hartman, University Hospitals, Iowa City, Iowa: Reviewing paper by Llewelyn-Davies.

One of the curious paradoxes in planning for health facilities in the mid-20th century is the fact that the planner knows full well that the facilities and equipment being included in the design may be functionally obsolete a year, a month, or even the day after completion of the project.

Application of the scientific method to the research paradigm dictates that the most basic level must be the descriptive or factual. This level of research occasionally involves expressions of a qualitative nature, but more usually the interpretations are solely quantitatively oriented. . . . The second level is the developmental, and has as its primary concern the design and construction of new materials, devices, or systems. . . . The highest level of research, and that which is the most difficult to attain, is the conceptual level.... Research, at this plane, provides a threshold for the development of a theoretical framework, which permits the integration of seemingly unrelated and independent elements.

The conceptual level of research activity must provide the course and direction of future research. Full awareness and acceptance of this premise provides a realization that research must not be conducted in a fragmented environment. Research and development must not be allowed to drift aimlessly, subject only to individual whim and preference.

Rather, future research activities, as they relate to facilities and equipment for health services, must be tightly coordinated, on an international basis, in a system of program analysis. This network of program analysis must delineate specifically the goals and purposes of 
the individual investigations and recognize the interrelationship of the individual undertaking to the aggregate research effort.

Lack of communication and cross fertilization acts as a very definite impediment to further advances in conceptual research and theory construction. . . A A realistic solution to this difficulty may be the development of an international health information retrieval system.

R. W. Revans, European Association of Management Training Centres, 53 Rue de la Concorde, Brussels, Belgium; research fellow, Guys Hospital, London: Research in hospital management and organization.

One of the most obstinate of all hospital problems ... is the cult of individualism among the medical staff.

The main research problem is that of defining, analyzing, and modifying the attitudes of those who, in our hospitals, hold the positions of power.

In the real world of suffering and anxiety, shared by staff no less than by patients, academic or scholarly studies that do not lend themselves to improving the human condition have no place. They may be brilliant excursions into the fields of statistics, anthropology, economics, or social theory, but if they do not help to resolve the problems of hospital effectiveness they are not researches into management or organization.

We shall understand these management problems only if and when those who are actually managing personally join or even wholly take over the research needed to resolve the problems. They will do this only when they want to do it, and this demands a radical change of view, to recognize that there is no salvation by outside experts. Action research, in the final analysis, alone can help. Insofar as the shouts of the bystanders do not confuse the runner, they may encourage him, but only his own efforts will get him past the winning post.

Obstacles to improvement are rarely those of failing to master the expertise of work simplification: They are a fatal inertia in applying it, through a long familiarity with a status quo that has forgotten how to question the obvious.

It is not unknown in British hospitals for patients occupying surgical beds to wait up to 2 weeks for a barium meal because the X-ray department is said to be overloaded.

Research ... leading to new methods of problem definition and resolution will never entirely replace intuition-thought below the level of consciousness-but . . . it will certainly free the experienced administrator to use his precious time and still more precious judgment both where it is needed most and upon issues that have been fairly clearly defined for him. The systems analyst will always face a residue of questions demanding the judgment of experience other than his own, and it is this residue that is the true province of the administrator. This is, perhaps, too clear an illustration of the difference between the science and the art of administration to need elaboration at this point, but it is very desirable to stress that research into the behavior of complex sequential systems shows that human intuition is singularly unable to forecast at all accurately how they are likely to respond to different forms of managerial intervention.

Increasing the number of nurses available to a ward may not in any way increase the amount of attention devoted to the patient, but merely increase the extent to which the nurses talk to each other.

"The Improvement of Patient Care," by Marian Wright [Putnam, 1964] is . . . written in simple language, entirely free of jargon. It may read at times more colorfully than the rigorous austerities of the professional research worker, with his tormenting demands for statistical significance. But for the matter in hand, which is to get those in charge of our hospitals both enthusiastic and informed about how more clearly to perceive, and more effectively to treat, their problems where they exist, it is unsurpassed.

It is, for the moment, no less important to encourage the gradual encroachment of ideas 
than to aim at specific technical achievements here and there.

It is, of course, a gross oversimplification to describe the interrupted and labyrinthine traffic in facts and misunderstandings between, say, 2,000 employees and 1,000 patients as a "communication system." The expression, moreover, is not only too gross in this respect, but it tends to give objectivity to what is essentially highly subjective.

The important elements in the communication system are not the actual channels of transmission-the forms, files, telephones, colored lights, nor even the subcommittee structuresbut the input and output mechanisms of those at the ends of such channels. It is the perception they hold of their place in the system, their awareness of how this role is seen by others, and the capacity to make themselves clear, not in some absolute language of objective precision but to the person in front of them, that determine most strongly whether their acts of communication will succeed.

Administrative action itself is not an exact and mechanical application of formal rules laid down by experts, but is of itself both a cure and an education.

Hospital administration on both sides of the Atlantic has embarked upon an anticipatory program of cultural change, as some ancient clock, by its overture of uneasy flutterings, proclaims that it is about to chime the hour.

The concept of the "therapeutic community," namely, an institution in which the governing element not only knows what is actually going on but is also itself capable of learning from this knowledge, as well as teaching its subordinates, may prove to be one of the discoveries of the mid-century - a broom strong enough to sweep our administrative ceilings clear of the last cobwebs of such once-powerful ideas as the charismatic leader, the divine right of kings, the philosopher crown princes of Plato's Republic and even, perhaps, some of the sterile ratiocinations taught in our contemporary schools as "the principles of management."
If one lives within a system that makes it impossible to define what needs doing, or that discourages one from the doing of it should it become defined, then one learns nothing. A failure to solve today's problems not only leaves us with that same problem tomorrow, but it actually disqualifies us even further from seeing what the fresh problems of tomorrow may be.

The myth of Babel offers fruitful lessons to the specialists, not in the modern hospital alone but in all institutions that depend for their success upon exploiting the obscure and reluctant secrets of modern science. Hence the importance ... of the stress put on communication, not solely for transmitting the necessary operational facts but for engendering the yet more necessary social processes of individual learning.

John and Elaine Cumming, in "Social Equilibrium and Social Change in the Iarge Mental Hospital" [Free Press, 1957] . . . show how ... the older staff . . . become vitally concerned with the maintenance of the status quo, and their natural enemy is the young and enthusiastic doctor, moved by such seditious hankerings as a desire to improve the treatment of the patients. Their method of dealing with the revolutionary is characteristic; namely, to deprive him of information about what is going on, or to obscure from him any procedural rules by which the institution is normally guided.

The structure of the organization is undermined by the extent to which communication takes place in informal rather than formal channels, and the worse communications are, the more likely this is to happen.

Only unusual people pause to examine the obvious.

Studies like those of Georgopoulos and Mann ["Community General Hospital," MacMillan, 1961] should be more widely known, not only for the good of the hospitals and their patients, but as part of a wider assault upon those arsenals of revealed dogma known as theories of management. 
Staff stability and patient recovery are functions of the communication system and, in particular, of the learning opportunities that the system offers.

What, we must now ask ourselves, does all this effort suggest for the future of research into hospital management and organization? We can answer this question by treating it as an exercise in decision theory and so asking three essential subquestions: $(a)$ What do we want to do? (b) What is stopping us from doing it? (c) What means have we at our disposal?

The answer to the first is that we want to stimulate as effectively as we can the natural recovery processes of the individual by bringing to bear on him that program of stimuli optimal to his condition and to the resources of the hospital. The second is that our principal handicap is an inadequate command of those sciences and arts that determine both the relations of individuals to the systems in which they work and the interactions between the elements of those systems. And the third is that, in the last 20 years we have been taught two lessons; namely, to seek ideas from any school interested in how human beings interact with each other and to grasp the pragmatic truth that only by action do we learn to master the hard and existential world. And it is by these three questions that our choice of future studies should be made.

Charles D. Flagle, Johns Hopkins University, Baltimore, Md.: Reviewing paper by Revans.

Dr. Revans has emphasized the importance of research in the subjective aspects of communication in organization. He mentions only in passing the systems analyses which are concerned with the objective substance and dynamics of communication and response.

The objective content of communication cannot be ignored safely, particularly at the scene of patient care. The widespread trend in hospitals toward centralized ancillary support of nursing units has forced an increase in the dependency of those units on schemes of administrative communication and coordination with external agencies. In turn, an increased demand has been placed on administration to develop information generation and flow systems which permit timely and adequate support of the patient care process. As these systems are in fact being developed, they not only provide data for ad hoc patient care but also contribute to bodies of statistics useful in planning, in study of response to therapy, and in studies of sensitivity and specificity in diagnosis and screening.

\section{W. Richard Scott, Stanford University, Stanford,} Calif.: Reviewing paper by Revans.

The building of basic theory requires simplification: dealing with a few variables at a time, selecting out for attention what may appear to the practically minded to be "trivial" events, and so on. 'The end product of this activity, if successful, is a highly general set of abstract principles, applicable to many kinds of phenomena, but totally accounting for none of them. By contrast, finding solutions to particular problems requires the investigator to deal with the phenomena to be explained in all their complexity. Interdisciplinary approaches are often called for. The end result of these efforts, if successful, is a remedy for the particular problem, but one which is applicable only to the specific situation or type of situation explored. Thus, to my mind at least, basic and applied or action research lead off in very different directions; and more particularly, action research is badly suited for the development of general principles.

It is far easier and much more efficient to change structural arrangements within organizations than it is to change directly the beliefs and attitudes of participants. Thus, a new division of labor or a new system of evaluation may be introduced that will change the behaviors and, eventually, even the attitudes of participants.

Structures within which professionals share with administrators responsibilities for the allocation and evaluation of the central organizational tasks are becoming increasingly common in highly industrialized societies, and no type of organization reflects this dual control structure more clearly than do hospitals. 